\title{
Student perceptions and reported use of video recorded lectures in engineering courses
}

\author{
Alan L Steele ${ }^{1}$ and Cheryl Schramm ${ }^{2}$ \\ ${ }^{l}$ Dept. of Electronics, ${ }^{2}$ Department of Systems and Computer Engineering, \\ Carleton University, 1125 Colonel By Drive, Ottawa, ON, K1S 5B6 \\ lasteele@,doe.carleton.ca and ${ }^{2}$ schramm@sce.carleton.ca
}

\begin{abstract}
Between 2008 and 2010 an introductory circuit analysis course for second year engineering students had its lectures recorded (2008 was audio only, other years were by video) and the recordings were made available to registered students as a supplemental resource. Attendance to lectures was still required. In 2011 an introductory programming course was recorded in a similar way. In each of these offerings the students were anonymously surveyed at the end of the course using an online survey tool with most questions using a five point Likert category scale. The survey looked at the perceived usefulness of the recordings, the approach to watching and the impact on attendance. The responses showed strong support to having video lecture capture and the reported use of the videos was to watch selected material. There was a difference between the courses on the impact on attendance, with the circuit analysis course indicated little impact on attendance, whereas the responses from the other course indicates more missed lectures due to the availability of recordings.
\end{abstract}

Keywords: Lecture capture, podcasting, engineering education, student survey, attendance.

\section{INTRODUCTION}

For those of us who have taught for a while, and perhaps our students who are now instructors, Powerpoint presentations swept through undergraduate education as a way to release students from the tyranny of note-taking, allowing them to focus their concentration on the lecture. While still pervasive, there is now considerable anecdotal and empirical evidence that there is a disconnect between the intent of the instructor and the perceptions of the students regarding Powerpoint lectures: Students perceive the Powerpoint slides to represent the important content of the course and demand their posting to avoid notetaking whilst instructors tend to view "... the whole presentation [as] important and what's up on the screen is just an illustration of a point or complementary, it certainly is not the whole thing." [6].
With the advance of classroom technology, Powerpoint presentations are giving way to (or being augmented by) lecture capture. Video Lecture Capture (VLC) comes in many shades; from webcasts of powerpoint slideshows, video recording of the lecturer, narrated screen-capture software, to full video recording of the classroom with camera operators. Research studies, including our own, are collecting and analyzing data concerning the viewing habits of students and impact of VLC on classroom attendance and performance. In this paper, we focus on the perceptions of the students. Like Powerpoint presentations, the intent of the instructors, and of the administration, interplay with the perceptions of their students. It is our motivation to capture the perceptions of the students, and explore them vis-à-vis the intent of the instructors.

Motivation for the work itself is in part similar to that of [10] who turned to VLC to address struggles with withdrawal and failure rates, a lack of course engagement, and troublingly low retention. The rationale for their work was partly based on cognitive load theory and the notion of dual video and audio pathways, each pathway being a separate cognitive process with its own load limit [5]. The implementation of VLC was seen to provide students a means to review course material at a speed under one's own control, allowing each student to regulate their learning according to their personal load limits. A majority of students did perceive strong learning benefits from the availability of recorded lectures, indicating that they were valuable for preparing for class, quizzes and exams, both because of their convenient access and by clarifying concepts covered in class. Yet, the results also indicated a statistically significant difference between students' perceptions about their performance as a result of the use of recorded lectures and the perceptions of the faculty. Faculty agreed that convenient access does have benefits, but contended the preparation value and particularly the effectiveness of VLC to clarify. The paper does not provide the details, but the faculty's lack of confidence in the presentation and clarification values of VLC perhaps indicates that technology cannot fix everything, that simply reviewing the same lecture again 
is not the kind of review that promotes learning; or, perhaps, students do not in fact watch the recording lectures to review, but for the first time. A concluding recommendation of Toppin's work was to do more work to "close that gap and to insure that students' perceptions about their performance are more realistic." [10].

In [10], the effect of VLC on classroom attendance was minimal, if not positive, conforming to much of the literature $[3,4,7,8]$. In contrast, [11] found that webcasting did in fact negatively affect attendance but to a lesser degree than posting Powerpoint lecture notes. Of note, though, their research also showed webcast lectures nullified the proven negative effects of absenteeism on performance - there was no net difference in the performance between the class with access to webcast recorded lectures and the class without, despite lower attendance in the webcast class. The result is interesting in two ways. First, if one can mitigate the decline in attendance reportedly brought on by VLC with other classroom strategies, such as pop quizzes, the findings suggest that there is a potential to achieve a net gain in performance. Second, despite no net change in their performance outcomes, students nonetheless reported positive learning experiences and benefits. Two thirds of these students agreed that webcasts were important to their overall satisfaction in the course and $87 \%$ would recommend that other students take courses that use webcasts. Students used the webcasts for expected reasons, such as missing a class or review, but also $69 \%$ of student reported that webcasts reduced their anxiety. Overall, course satisfaction increased and comments credited "webcasts [as being] one of the most effective learning resources" [11]. Other studies similarly report a uncertain impact of webcasts on student performance coupled with strongly positive student perceptions of their effect on their learning, their study efficiency and on their exam performance $[1,2]$.

There seems to be a dichotomy behind the emphatic endorsement by students and a lack in real performance improvement that is worthy of exploration. It is encouraging to see the positive perceptions of the students which may provide fertile ground for more radical shifts to classroom learning. In $[9,11]$ recorded lectures were streamed to students beforehand, so that the class time was available for hands-on interactive classroom activities. When compared to a second class run in the traditional lecture style, a significant performance gain was seen in the first class.

On the cautionary side, perhaps we need to teach students how to use the VLC technology. Our own studies show that access rises dramatically before exams because students perceive that VLC webcasts are a good study tool. Perhaps we need to investigate whether this is true and perhaps we need to train them in the use of captured lectures. Is viewing the same as studying?

The two courses selected for the introduction of video captured lectures were Summer offerings and outside the normal academic course path. These courses were used by students who were needing the course due to failure, reaching ahead or other reasons that had made the students off the regular course pattern. One feature of these Summer courses was the shortened period over which the course is delivered (half the normal time) and the corresponding doubling of the weekly contact hours. Like all engineering courses, a substantial amount of material is covered, but both courses are introductions to new fields of knowledge (one, electronics; one, programming) requiring a large leap in learning. The new ideas demand a high cognitive load. Reviews, spread over time, help students to digest the material in smaller sections, at their own rate. The video recorded lectures would provide a tool for independent review.

The research questions raised were would students use the video recordings and in what way? What is the perceived usefulness of the recordings? How did it compare to other aspects of the course? The affect on attendance (from the students perspective) could be examined too.

This report presents results from a study that has progressed over several years, on two courses taught by different instructors. A similar methodology is used with some variations with procedure (and data collection). In both, an augmented video classroom [6] was used in the study, meaning that the video lecture recordings were provided as a supplementary learning resource, not to replace face-to-face class time. Classroom attendance was still mandatory for all lectures. Lectures were recorded in fully equipped video classrooms by video technicians. Recordings were posted within a day after the lecture on the courses' learning management system. The results from the two courses provide a collection of experiences over multiple years, between undergraduate courses at Year 1 and 2, and between a core engineering course and more specialized introductory course.

The context and detailed methodology of each of the two courses are described separately in Section 2. Section 3 considers the survey results, again presented in series for the two courses. Section 4 summarizes the principle findings.

\section{COURSES RECORDED AND SURVEYED}

\subsection{Circuits and Signals, ELEC2501}

Students undertaking an engineering program at Carleton University that involves some element of electrical engineering are required to take a second year course in Circuits and Signals (course code ELEC 2501). This course is an introductory circuit analysis course and runs in the Fall and also with a smaller cohort in early Summer. This later offering is taken by students wanting to reach ahead, those that started in a Winter term and need to get on a normal Fall start pattern and those that need to retake the course. It is the Summer offering that was video recorded in the years 2009 and 2010, as well as having audio recordings 
being made in Summer 2008. For each of those years an online survey was made using the GetFast online survey tool (now Toofast.ca). Although initially only intended to be a single term feedback tool the survey was repeated over the three years with similar questions. This allowed the comparison to be made to the responses over that time.

For 2008 the recording of the classes was the audio recording of the lecturer's voice. These recordings of the whole class were posted after the classes. In 2009 and 2010 the classes were video recorded by a video technician from the back of the room. There was also recording of the computer display and an overhead camera was used over the podium desk so that notes and other presentation material were recorded. A final camera mounted towards the front of the class which could record the seated students in the lecture room. Switching between cameras, as well as split picture combinations was done by the technician as the recording was made.

For each year the recorded lectures were posted on the course learning management system (LMS) usually within one or two days of the lecture happening. Students could then refer back to the recordings and review material as they wished. The video recordings could not be downloaded but were streamed on demand from facilities within the Carleton University Online Learning unit.

To attempt to understand how students found the use of these recordings questions were included in an instructor generated online survey. This survey asked for feedback on different aspect of the course, including questions on the text book, the LMS, laboratories and the recordings. Questions were mostly on a Likert-type scale. These will be explained in section 3 .

\subsection{Problem solving with computers, ECOR1606}

ECOR1606 is a core introductory course for all engineering students. It uses the $\mathrm{C}$ programming language to solve simple engineering related problems. The course serves two roles, one to introduce programming skills and the other to develop the problem solving abilities of engineering students. Because of the programming content there appears to be a wide range of student engagement, arguably more spread than the other course.

The course surveyed was a Summer course that was provided for people to take in advance of the main academic year or for those that wanted to retake the course. Like the ELEC2501 course, all the lectures were video recorded, this time by two technicians. As the lecture theatre was relatively large (approximately 400 seats) one camera and its operator were positioned in the middle aisle of the theatre. Another operator worked from a rear booth and controlled an overhead camera (to film materials on a desk) and the recording of a computer screen.

A survey questionnaire was prepared by the authors (one being the course instructor for ELEC2501 and the other the instructor for ECOR1606), with some questions similar to the ELEC2501 survey and others unique to the ECOR1606 course.

Ethical clearance was obtained to survey the attendance and video access of a self selected group of students. The online survey questionnaire was part of this study. Unfortunately, the collection of the attendance data became increasingly inaccurate over time, so correlation of the use of the videos to attendance could not be made.

\section{RESULTS AND DISCUSSION}

Here we will give the questions asked and the cumulative responses. Since the courses were different the surveys and the results will be grouped into two separate sections. Discussion and comments on the data will be made in this section and conclusions drawn in the next section.

\subsection{Circuits and Signals, ELEC2501, survey}

The survey, for this course, over the three years was very similar with changes focusing on the move from audio recordings to video recordings. The number of students in a given year's class and the corresponding number of the responses are given in Table 1 . It can be seen that there was a response of over $50 \%$ but under $75 \%$ each year. To facilitate comparison each the survey results were placed into percentage of the respondents.

Table 1: Class size and response

\begin{tabular}{|c|c|c|}
\hline Year & $\begin{array}{c}\text { Number of } \\
\text { students in class }\end{array}$ & $\begin{array}{c}\text { Number of } \\
\text { responses }\end{array}$ \\
\hline 2008 & 29 & 19 \\
\hline 2009 & 33 & 18 \\
\hline 2010 & 40 & 24 \\
\hline
\end{tabular}

Two early questions looked at the text book and the learning management system (Moodle), see Fig. 1 and 2 respectively. 


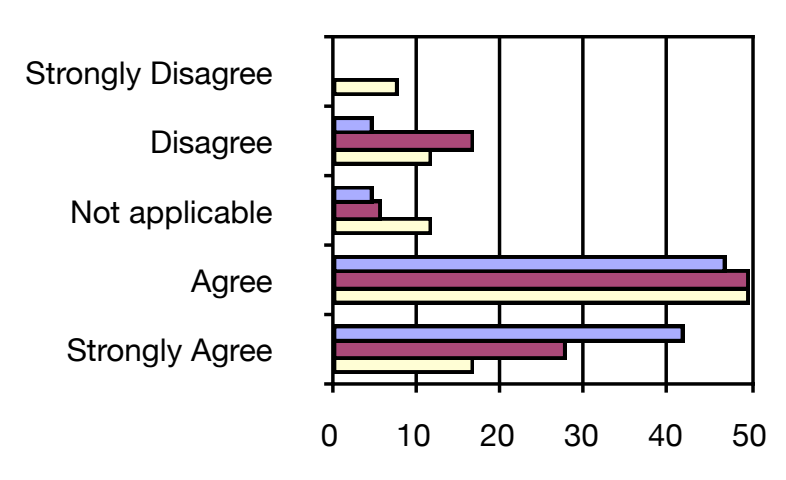

Percentage of respondents

\section{9}

$\square 2010$

Fig. 1. Responses to the question "The Textbook was a useful resource for the course".

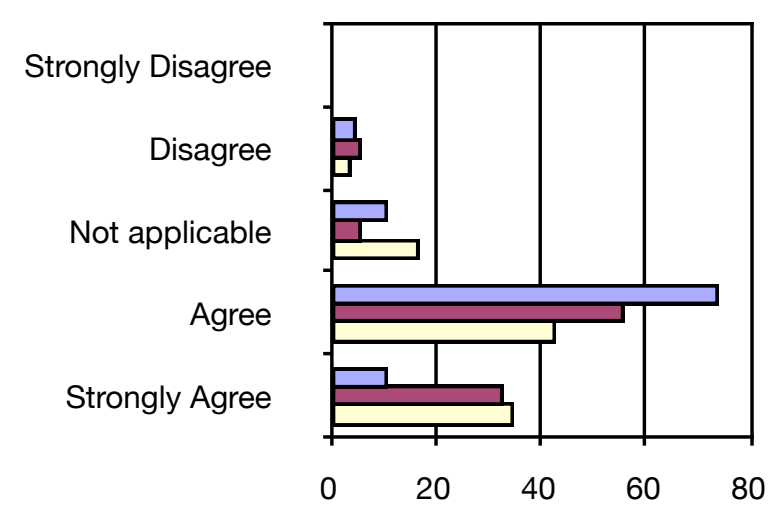

Percentage of respondents

\begin{tabular}{|lll|}
\hline$\square 2008$ & $\square 2009$ & $\square 2010$ \\
\hline
\end{tabular}

Fig. 2. Responses to the question "The Moodle website enhanced the instruction I received".

As could be anticipated there was strong agreement that the course text book and the course LMS, Moodle, were helpful resources. Although it can be clearly seen that there is a fall in the number of 'strongly agree' for the textbook question, Fig. 1, over the three years. Whereas, that category rises over the three years for the 'Moodle' question, Fig. 2.

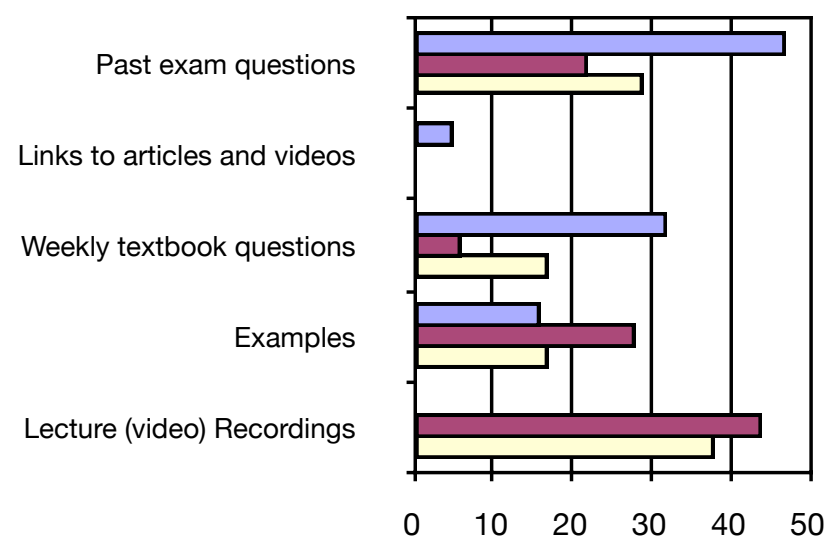

Percentage of respondents

\begin{tabular}{|lll|}
\hline$\square 2008$ & $\square 2009$ & $\square 2010$ \\
\hline
\end{tabular}

Fig. 3. Responses to the question "What part of the course website did you find the most useful?".

Which aspects of the website were deemed the most useful to the students was investigated with the question and results shown in Fig. 3. Here there is a spread of what parts the individual students found useful, however the rise of the video recordings in 2009 and 2010 are quite notable. Especially as the audio recordings in 2008 were not rated as the most important by any of the responders. It should be clarified that in the final response category the word 'video' is included in parenthesis since in the 2008 survey it was absent in the response category (as it was audio recordings that were made), but was included in the later two surveys. The past exam questions were selected questions from the previous year's exam, that were released usually one a week and that question related to material covered in the course that week.

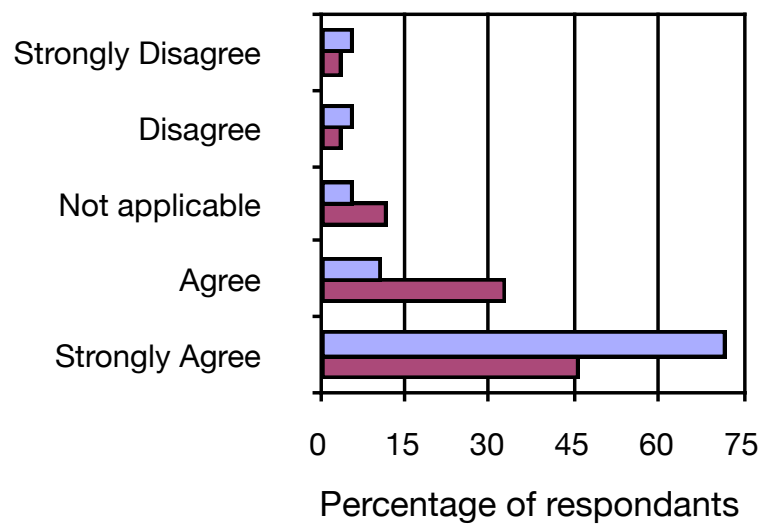

2009 2010

Fig. 4. Responses to the question "All classes should be video recorded and made available". 
When asked for their opinion on whether all lectures should be video recorded and made available on a Likert scale the response was largest in the strongly agree category, Fig. 4. This is perhaps not too surprising as a clear record of lectures, which can be used to review the lecture days or weeks after the class can be seen as an asset in trying to understand or review material. Fig. 5 shows the students stated approach to using the material. The most popular approach to using the videos was different for the two years of the recordings. In 2009 it was to "review selected material", whereas in 2010 it was to "review examples". The common feature for these reasons is the ability to review material. Watching to catch up on missed lectures was popular in 2009 but considerably less in 2010.

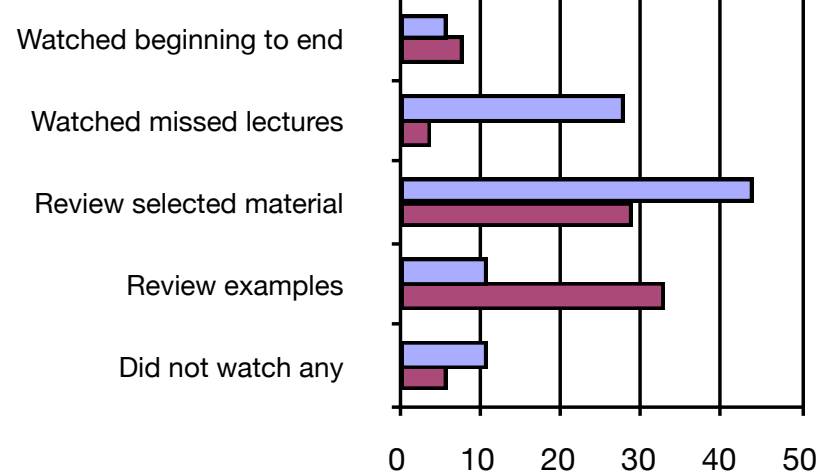

Percentage of respondants

\begin{tabular}{|l|l|}
\hline$\square 2009$ & $\square 2010$ \\
\hline
\end{tabular}

Fig. 5. Responses to the question "How best describes how you used the video recordings".

The surveys also asked students to explain how the the video recordings had affected their attendance. The answer options were relatively long and for brevity have been shortened in Fig. 6. The full survey options were (in order given in Fig. 6.); 'It did not affect my attendance', 'I missed an occasional class and it allowed me to catch up', 'It reduced my attendance partially', 'I missed the majority of the classes for reasons other than the recordings', 'I missed the majority of the classes as the recordings were available'. Here the response was to indicate that for the majority it did not affect attendance and the other most popular reason was that an occasional class was missed but the recordings allowed the catch up on the material.

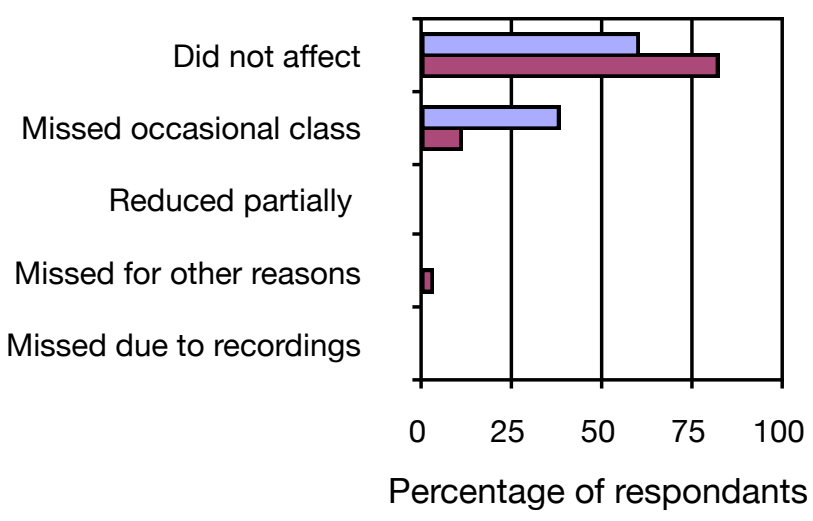

\begin{tabular}{|l|}
\hline$\square 2009$ \\
\hline
\end{tabular}

Fig. 6. Responses to the question "How best describes how the availability of lecture recordings affected your attendance"

In an attempt to compare the perceived usefulness of the recordings students were asked to rate on a Likert scale 'how $x$ enhances my understanding of the subject matter', where $x$ was the laboratory, problem analysis sessions or the video recordings. Tables 2 to 4 have the response for 2008 (where a response for the audio recordings was not made) to 2010 respectively. In the three tables it can be seen that although there was agreement that the tutorial and laboratories enhanced the understanding of the material, the videos for both of the years surveyed showed a high level of strong agreement for the enhancement of the understanding.

Table 2: Percentage response in 2008 to the question 'how $x$ enhances my understanding of the subject matter'

\begin{tabular}{|l|c|c|}
\hline \multicolumn{1}{|c|}{ Response } & Tutorial & Laboratory \\
\hline Strongly Disgree & 0 & 0 \\
\hline Disagree & 21 & 11 \\
\hline Not applicable & 0 & 32 \\
\hline Agree & 63 & 32 \\
\hline Strongly Agree & 3 & 26 \\
\hline
\end{tabular}

Table 3: Percentage response in 2009 to the question 'how $x$ enhances my understanding of the subject matter'

\begin{tabular}{|l|c|c|c|}
\hline \multicolumn{1}{|c|}{ Response } & Tutorial & Laboratory & Video \\
\hline Strongly Disgree & 0 & 0 & 0 \\
\hline Disagree & 0 & 0 & 0 \\
\hline Not applicable & 6 & 6 & 17 \\
\hline Agree & 67 & 72 & 33 \\
\hline Strongly Agree & 28 & 22 & 50 \\
\hline
\end{tabular}


Table 4: Percentage response in 2008 to the question 'how $x$ enhances my understanding of the subject matter'

\begin{tabular}{|l|c|c|c|}
\hline \multicolumn{1}{|c|}{ Response } & Tutorial & Laboratory & Video \\
\hline Strongly Disgree & 12 & 8 & 0 \\
\hline Disagree & 12 & 8 & 8 \\
\hline Not applicable & 17 & 33 & 21 \\
\hline Agree & 54 & 46 & 42 \\
\hline Strongly Agree & 4 & 4 & 29 \\
\hline
\end{tabular}

\subsection{Problem solving with computers, ECOR1606 Survey}

The class size for the Summer 2011 offering of this course was 94. The response to the survey done in the Fall, after deferral exams had been completed was only 16. Therefore the survey was for only a small subgroup of the overall class and so could be not representative. However, the comparison to the ELEC2501 course findings could be interesting to see if there was a similar or different trend. As the response count was so low and was only for one year there has not been an attempt to put the responses into percentages and instead the number of responses are given in tabulated form, see Table 5.

The data shows that 4 of the respondents did not watch the recordings at all. Despite that, all agreed with the statement that 'all lectures should be video recorded', with 10 of the 16 agreeing strongly. This matches the findings, Fig. 4, with the circuits course.

Only 2 of the 16 watched all the videoed lectures and those that watched them were watching selected material or reviewing examples. Casual viewing was done only by 2 responders and the majority were viewing to help understand material. One person declared they watched to try and master the material. Two indicated they watch the videos from the beginning of the course, others started at different points following with most using them at the middle of the course. When asked to rate the usefulness of the recordings on a five point scale, three rated them at 1 , the lowest, whilst 6 rated them 5, the highest. ELEC2501, a significant number, 7 of the 16, indicated they missed a lecture because they knew that the recording would be available.

Table 5: Results of the 16 responses for the ECOR1606 survey. Questions are given in bold in the row preceding the answer and response number.

\begin{tabular}{|l|c|}
\hline $\begin{array}{l}\text { Did you find the video recordings } \\
\text { available useful? }\end{array}$ & Responses \\
\hline Yes & 11 \\
\hline No & 5 \\
\hline $\begin{array}{l}\text { Approximately how many lecture videos } \\
\text { have you watched? }\end{array}$ \\
\hline All & 2 \\
\hline
\end{tabular}

Interestingly, and in contrast to the findings with

\begin{tabular}{|c|c|}
\hline Most & 6 \\
\hline Just a few & 4 \\
\hline One & 0 \\
\hline None & 4 \\
\hline \multicolumn{2}{|l|}{$\begin{array}{l}\text { How best describes how you used the } \\
\text { lecture videos? }\end{array}$} \\
\hline Watched from beginning to end & 0 \\
\hline $\begin{array}{l}\text { Watched selected material I did not } \\
\text { understand in class }\end{array}$ & 10 \\
\hline $\begin{array}{l}\text { Watched mostly to review examples done in } \\
\text { class }\end{array}$ & 2 \\
\hline Have not watched any & 4 \\
\hline \multicolumn{2}{|l|}{$\begin{array}{l}\text { How best describes why you watched the } \\
\text { lecture videos? }\end{array}$} \\
\hline To catch up on lectures I was absent from & 0 \\
\hline $\begin{array}{l}\text { To help with difficult material I do not } \\
\text { understand }\end{array}$ & 9 \\
\hline To master material I already understand & 1 \\
\hline To casually review the lecture & 2 \\
\hline I have not watched any & 4 \\
\hline \multicolumn{2}{|l|}{$\begin{array}{l}\text { At what point did you start watching the } \\
\text { videos? }\end{array}$} \\
\hline At the start & 2 \\
\hline After coursework was set & 3 \\
\hline About midway through the course & 6 \\
\hline At the end before the exams & 1 \\
\hline None were watched & 4 \\
\hline \multicolumn{2}{|l|}{$\begin{array}{l}\text { On a scale of } 1 \text { (lowest) to } 5 \text { (highest) } \\
\text { please rate how useful you found having } \\
\text { the lecture videos available }\end{array}$} \\
\hline 1 & 3 \\
\hline 2 & 1 \\
\hline 3 & 3 \\
\hline 4 & 3 \\
\hline 5 & 6 \\
\hline \multicolumn{2}{|l|}{$\begin{array}{l}\text { Did you miss an ECOR1606 class (not } \\
\text { due to sickness) because you knew it } \\
\text { would be available on video? }\end{array}$} \\
\hline Yes & 7 \\
\hline No & 9 \\
\hline \multicolumn{2}{|l|}{$\begin{array}{l}\text { How do you agree with the following } \\
\text { statement? "All lectures should be video } \\
\text { recorded" }\end{array}$} \\
\hline \begin{tabular}{|l|} 
Strongly agree \\
\end{tabular} & 10 \\
\hline Agree & 4 \\
\hline Neither agree of disagree & 2 \\
\hline Disagree & 0 \\
\hline \begin{tabular}{|l} 
Strongly Disagree \\
\end{tabular} & 0 \\
\hline
\end{tabular}




\section{CONCLUSION}

We have reported on the anonymous student opinions on the recording of two different courses. The courses were a second year electrical circuits course, recorded three years in succession, and a first year introductory programming course, recorded once. The reply success to the survey request was over $50 \%$ for the circuits course, whereas the programming course had a low response (less than $20 \%$ ).

The survey responses show that video recording is viewed as a very useful resource. There is strong support for the suggestion of having all classes video recorded. Something that has significant practical implications if a university implemented this. Recordings are reported as mostly being used to review selected material or examples. The survey responses in the programming course indicated that the recording helped with understanding difficult material.

Self reporting on the impact of their own attendance showed a difference between the two courses. The second year circuits course over the three years showed that the recordings had little impact on the attendance, whereas the single year of the first year programming course showed a higher impact on attendance. This raises an interesting question as to why. One possibility is due to different course instructors, although both were experience faculty and both had been awarded university teaching achievement awards. Other factors could be size of the classes, the year of the course, sample size (so not representative) or the degree of interest in the subject matter.

In the circuits course some interesting results show the perceived usefulness of the video recordings in comparison with the other integral parts of the course, the laboratories and the problem analysis tutorial sessions. Here the recordings were repeatedly viewed as being more useful than the more conventional parts of the course. It is interesting to speculate why this is. Perhaps it is because the exam has a significant weighting on the final course grade. Maybe the students feel the need for more time to assimilate the circuit analysis theory. This is perhaps supported by the use of reviewing selected parts of the recordings. This perception of the usefulness of the various aspects of the course is potentially worth investigating further.

It should be said that this data is self reported by the responders. This may or may not accurately reflect what actually happened, for example with attendance. There may be an element of supplying responses that those surveyed think are expected, or hoped for, by the questioner. However, there are repeated trends that are occurring that indicate strong support in having a recording of the actual lecture for review.

Should lectures and classes be recorded? There is a significant practical issue with doing this, especially to having a video classroom, as used in this study. However, there are developments with computer screen capture technology and audio recording which could make VLC practical in most classrooms and possible for a relatively low cost.

\section{Acknowledgements}

The authors would like to acknowledge the staff of Carleton University Online and Educational Development Centre for their support and technical assistance with the video recording.

\section{References}

[1] C. Acharya, (2003). "NUSCast survey", Paper presented at the conference on human factors in computing systems, Montreal, Canada, 2003), 2003. . Retrieved February 1, 2008 from https://team.nus.edu.sg/cdtl/staff/Research/ CDTLMSNo_4.pdf.1005361.1005362.

[2] J. Brotherton and G. Abowd, "Lessons learned from eclass: Assessing automated capture and access in the classroom" in ACM Transactions on Computer-Human Interaction, vol. 11 no. 2, pp. 121-155, 2004. . doi:10.1145

[3] L. Briggs, "Classroom Capture: Lecture Recording System Draws Devotees at Temple". 2007. Retrieved January 20, 2010, from http://campustechnology.com/articles/2007/02/ classroom-capture-lecturerecordingsystem-draws-devoteesat-temple.aspx.

[4] K. DeAngelis, "Lecture Capture: Student Opinion and Implementation Strategies", 2009. Retrieved January 20, 2010, from http://teaching.uncc.edu/resources/tipsheets/ lecture-capture

[5] Robert A. Ellis, Peter Goodyear, Rafael A. Calvo and Michael Prosser, "Engineering students' conceptions of and approaches to learning through discussions in face-to-face and online contexts" in Learning and Instruction Vol. 18 pp. 267-282, 2008.

[6] Maria José M. Ferreira, Intelligent classrooms and smart software: Teaching and learning in today's university" in Education Information Technology, vol. 17, pp. 3-25, 2012. Published online: 23 September 2010

[7] S. Kolowich. "Fans and Fears of Lecture Capture". 2009. Retrieved January 20, 2010, from http:// www.insidehighered.com/news/2009/11/09/capture.

[8] A. McClure. "Lecture Capture: A Fresh Look", 2008. Retrieved January 20, 2010, from http:// www.universitybusiness.com/viewarticle.aspx? articleid $=1043 \& p=1$

[9] Amber Settle, Lucia Dettori and Mary Jo Davidson, "Does lecture capture make a difference for students in traditional classrooms" in Proceedings of the 16th annual joint conference on Innovation and technology in computer science education (ITiCSE'11, New York). 2011

[10] Ian N. Toppin, "Video lecture capture (VLC) system: A comparison of student versus faculty perceptions" in Education Information Technology, vol. 16, pp. 383-393, 2011. Published online: August 2010. 
Proc. 2012 Canadian Engineering Education Association (CEEA12) Conf.

[11] Tomoko Traphagan, John V. Kucsera, and Kyoko Kishi, "Impact of class lecture webcasting on attendance and learning" in Education Technology Research Development vol. 58, pp. 19-37, 2010. 